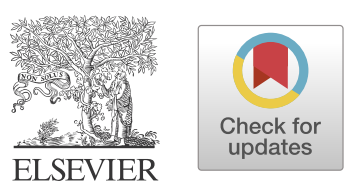

CJC Open 3 (2021) 1169-1181

\title{
Systematic Review and Meta-analysis \\ Direct Oral Anticoagulants vs Vitamin K Antagonists in Left Ventricular Thrombi: A Systematic Review and Meta-analysis
}

\author{
Faith Michael, MD, ${ }^{a, \ddagger}$ Navneet Natt, MD, ${ }^{a, \ddagger}$ and Mohammed Shurrab, MD, MSc $c^{a, b, c, d}$ \\ ${ }^{a}$ Northern Ontario School of Medicine, Laurentian University, Sudbury, Ontario, Canada \\ ${ }^{b}$ Cardiology Department, Health Sciences North, Sudbury, Ontario, Canada \\ ${ }^{c}$ Health Sciences North Research Institute, Sudbury, Ontario, Canada \\ ${ }^{d}$ Institute of Health Policy, Management and Evaluation, University of Toronto, Toronto, Ontario, Canada
}

\begin{abstract}
Background: There is increasing interest in direct oral anticoagulants (DOACs), given their safety and convenience in atrial fibrillation, compared with vitamin K antagonists (VKAs). However, the use of DOACs in left ventricular (LV) thrombi is considered off-label, with current guidelines recommending VKAs. The aim of this meta-analysis was to compare the safety and efficacy of DOACs to VKAs in the management of LV thrombi.

Methods: A systematic search was conducted for studies published between January 1, 2009 and January 31, 2021 in PubMed, Embase, and CENTRAL. Included studies compared DOACs to VKAs for the treatment of LV thrombi and reported on relevant outcomes. Odds ratios (ORs) were pooled with a random-effects model.

Results: Sixteen cohort studies and 2 randomized controlled trials were identified, which included 2666 patients $($ DOAC $=674$; VKA = 1992). Compared with VKAs, DOACs were associated with a statistically significant reduction in stroke (OR $0.63,95 \%$ confidence interval $[\mathrm{Cl}]$ 0.42-0.96; $P=0.03 ; I^{2}=0 \%$ ). There were no significant differences in bleeding (OR $0.72,95 \% \mathrm{Cl} 0.50-1.02 ; P=0.07$; $I^{2}=0 \%$ ), systemic embolism (OR $0.77,95 \% \mathrm{Cl} 0.41-1.44 ; P=0.41$; $I^{2}=0 \%$ ), stroke or systemic embolism (OR $0.83,95 \% \mathrm{Cl} 0.53-1.33$; $P=0.45 ; I^{2}=33 \%$ ), mortality (OR 1.01, 95\% Cl 0.64-1.57; $P=0.98$; $\left.I^{2}=0 \%\right)$ or LV thrombus resolution (OR 1.29, 95\% Cl 0.83-1.99; $\left.P=0.26 ; I^{2}=56 \%\right)$.
\end{abstract}

Left ventricular (LV) thrombus formation complicates $15 \%$ of acute myocardial infarctions (MIs), and it is even more common in conditions of impaired LV systolic function. ${ }^{1-3}$ If left untreated, up to $20 \%$ of patients can have significant complications,

Received for publication January 19, 2021. Accepted April 10, 2021.

Ethics Statement: The research reported has adhered to the ethical guidelines.

$\ddagger$ These authors contributed equally to this work.Corresponding author: Dr Mohammed Shurrab, Cardiology Department, Health Sciences North, Health Sciences North Research Institute, Northern Ontario School of Medicine, Laurentian University, 41 Ramsey Lake Rd, Sudbury, Ontario P3E 5J1, Canada.

E-mail: shurrabm@hotmail.com

See page 1180 for disclosure information.

\section{RÉSUMÉ}

Introduction : Les anticoagulants oraux directs (AOD) font l'objet d'un intérêt grandissant par rapport aux antagonistes de la vitamine $K$ (AVK) en raison de leur innocuité et de leurs avantages lors de fibrillation auriculaire. Toutefois, l'utilisation des AOD lors de thrombi du ventricule gauche (VG) est considérée comme non conforme selon les lignes directrices actuelles qui recommandent les AVK. L'objectif de la présente méta-analyse était la comparaison de l'innocuité et de l'efficacité des AOD aux AVK dans la prise en charge des thrombi du VG.

Méthodes : Nous avons réalisé une recherche systématique pour trouver des études publiées entre le $1^{\mathrm{er}}$ janvier 2009 et le 31 janvier 2021 dans PubMed, Embase et CENTRAL. Les études sélectionnées qui portaient sur la comparaison des AOD aux AVK dans le traitement des thrombi du VG ont rendu compte de résultats pertinents. Nous avons regroupé les ratios d'incidence approché (RIA) au moyen d'un modèle à effets aléatoires.

Résultats : Nous avons relevé 16 études de cohorte et deux essais cliniques à répartition aléatoire auprès de 2666 patients $(A O D=674$; $A V K=1992$ ). Par rapport aux AVK, les AOD étaient associés à une réduction significative sur le plan statistique lors d'accidents vasculaires cérébraux (AVC) (RIA 0,63, intervalle de confiance [IC] à $95 \%$ $0,42-0,96 ; P=0,03 ; I^{2}=0 \%$ ). II n'y avait aucune différence significative en ce qui concerne les hémorragies (RIA 0,72, IC à $95 \% 0,50-$ 1,$02 ; P=0,07 ; l^{2}=0 \%$ ), l'embolie systémique (RIA 0,77 , IC à $95 \%$ $0,41-1,44 ; P=0,41 ; l^{2}=0 \%$ ), les AVC ou l'embolie systémique (RIA

including stroke and systemic embolism. ${ }^{3}$ Current consensus guidelines recommend the use of vitamin $\mathrm{K}$ antagonists (VKAs) to treat LV thrombi following acute MIs for 3-6 months. ${ }^{4,5}$

Direct oral anticoagulants (DOACs) are a preferred alternative to VKAs, as they have lower bleeding rates, fewer drug interactions, rapid onset of action, and decreased need for monitoring. ${ }^{6}$ However, the use of DOACs for this indication remains off-label. Many observational studies have shown comparable safety and efficacy of DOACs to VKAs in the management of LV thrombi. $^{7-9}$ However, a recent large cohort study identified a higher risk of stroke or systemic embolism with DOACs, calling into question their use in the treatment of LV thrombi. ${ }^{10}$

The aim of this systematic review and meta-analysis was to compare the safety and efficacy of DOACs to VKAs in the 
Conclusions: Within the context of low-quality evidence, there was a statistically significant reduction in stroke among those treated with DOACs, without an increase in bleeding. There were no significant differences in systemic embolism, stroke or systemic embolism, mortality, or LV thrombus resolution, suggesting that DOACs may be a reasonable option for treatment of LV thrombi. management of LV thrombi. The primary outcomes of our review were stroke and bleeding, and secondary outcomes included systemic embolism (SE), stroke or systemic embolism (SSE), mortality, and LV thrombus resolution.

\section{Methods}

\section{Literature search and data sources}

A systematic search of the literature was conducted by 2 investigators (F.M., N.N.) in PubMed, Embase, and CENTRAL for studies published between January 1, 2009 and January 31, 2021. The PubMed search terms were: (DOAC OR NOAC OR anticoag* OR factor Xa inhibitor OR antithrombin OR rivaroxaban $\mathrm{OR}$ dabigatran $\mathrm{OR}$ apixaban $\mathrm{OR}$ edoxaban) AND [(left ventric* OR LV) AND (thromb* OR clot)]. The PubMed search strategy is available as Supplemental Appendix S1. Language restrictions were not applied. All studies obtained from the search were reviewed manually in duplicate (by F.M. and N.N.) for inclusion. We also searched for grey literature through databases (Scopus and OpenGrey), manual web searches, and conference proceedings, in addition to ClinicalTrials.gov for ongoing trials. The reference lists of relevant articles, including systematic reviews and meta-analyses, were hand searched.

\section{Study selection and quality assessment}

The following inclusion criteria were applied: (i) studies must compare DOACs to VKAs in the management of LV thrombi; and (ii) studies must report on outcomes of interest-stroke, bleeding, SE, SSE, mortality, or LV thrombus resolution. No restrictions were placed on the study population. We excluded noncomparative trials, case reports, case series, systematic reviews, and meta-analyses. Abstracts were included, and although authors were contacted for additional data, no unpublished data were obtained. The selection of studies was assessed independently by 2 investigators (F.M., N.N.). Disagreements between authors were resolved through discussion, and when required, consultation with a third author (M.S.).

The quality of the primary studies was assessed in duplicate (by F.M. and N.N.). The Newcastle-Ottawa Scale was used to evaluate cohort studies on selection of study groups, comparability of study groups, and measurement of outcomes. ${ }^{11}$ The Cochrane risk-of-bias 2 tool was used to evaluate randomized controlled trials (RCTs) on selection bias,
0,83 , IC à $95 \% 0,53-1,33 ; P=0,45 ; I^{2}=33 \%$ ), la mortalité (RIA 1,01, IC à $95 \% 0,64-1,57 ; P=0,98 ; l^{2}=0 \%$ ) ou la résolution du thrombus du VG (RIA 1,29, IC à $95 \% 0,83-1,99 ; P=0,26 ; I^{2}=56 \%$ ).

Conclusions : Dans le contexte de données probantes de faible qualité, il y avait une réduction significative sur le plan statistique en ce qui concerne les AVC chez les patients traités par AOD sans augmentation des hémorragies. Puisqu'il n'y avait aucune différence significative en ce qui concerne l'embolie systémique, les AVC ou l'embolie systémique, la mortalité ou la résolution de thrombus du VG, cela indique que les AOD peuvent être une option valable de traitement des thrombi du VG.

performance bias, detection bias, attrition bias, reporting bias, and other bias. ${ }^{12}$ Publication bias was assessed for the primary outcomes of stroke and bleeding (Supplemental Figs. S1 and S2).

\section{Data extraction and outcomes of interest}

Two investigators (F.M., N.N.) independently extracted the following data from included studies: study design, sample size, intervention, patient demographics, outcome data, and definitions of outcomes. Disagreements were resolved through discussion, and when necessary, consultation with a third author (M.S.).

The primary outcomes were stroke and bleeding. Secondary outcomes were SE, SSE (composite of stroke and/or systemic embolic events), mortality, and LV thrombus resolution. The definitions of outcomes are summarized in Table 1, for those described in the included studies.

\section{Statistical analysis}

The RevMan (version 5) software package provided by the Cochrane Collaboration was used for combining outcomes from the individual studies and for statistical analysis. ${ }^{13}$ Outcomes were pooled with the use of a random-effects model as described by DerSimonian and Laird. ${ }^{14}$ Summary estimates and 95\% confidence intervals (CIs) were reported for dichotomous variables as odds ratios (ORs). The heterogeneity between studies was assessed by means of Cochrane $X^{2}$ and $I^{2}$. An $I^{2}>50 \%$ was considered to represent significant heterogeneity. ${ }^{15}$ Statistical significance was set as $P<0.05$. Comparisons were calculated using the Student $t$-test. Given the limitations of conducting a metaanalysis with unadjusted event rates, we additionally performed a narrative synthesis of the data.

\section{Results}

\section{Literature search and characteristics of included studies}

The literature search yielded 3050 studies (937 from PubMed, 1903 from Embase, 205 from CENTRAL, and 5 from other sources, including grey literature, review articles, and reference lists). Duplicates were removed, and we excluded 2637 studies during title and abstract review. The remaining 30 studies were assessed in full text. Eighteen 


\begin{tabular}{|c|c|c|c|c|c|c|}
\hline \multirow[b]{2}{*}{ Author } & \multirow[b]{2}{*}{ Study design } & \multicolumn{2}{|c|}{ Groups } & \multirow[b]{2}{*}{ Etiology of LV thrombus } & \multirow[b]{2}{*}{ Average follow-up, mos } & \multirow[b]{2}{*}{ Outcome definitions } \\
\hline & & VKA, n & $\mathrm{DOAC},{ }^{*} \mathrm{n}$ & & & \\
\hline$\overline{\text { Abdelnabi }(2020)^{17}}$ & RCT & 40 (all warfarin) & $\begin{array}{l}39 \text { (all rivaroxaban, } 20 \mathrm{mg} \\
\text { daily) }\end{array}$ & $\begin{array}{l}\text { Ischemic cardiomyopathy } \\
\quad(78.5 \%) \\
\text { Idiopathic }(20.3 \%) \\
\text { Peripartum }(1.2 \%)\end{array}$ & 6 & $\begin{array}{l}\text { Stroke: Any type of stroke } \\
\text { SE: Any type of systemic embolism } \\
\text { Bleeding: Major bleeding } \\
\text { according to ISTH } \\
\text { LV thrombus resolution: } \\
\text { Determined by TTE }\end{array}$ \\
\hline Alcalai $(2020)^{18}$ & RCT & 12 (all warfarin) & 13 (all apixaban, $5 \mathrm{mg}$ BID) & Acute MI (100\%) & 3 & $\begin{array}{l}\text { Bleeding: Major bleeding } \\
\text { LV thrombus resolution: } \\
\text { Determined by TTE }\end{array}$ \\
\hline $\operatorname{Ali}(2020)^{21}$ & Retrospective cohort & 60 (all warfarin) & $\begin{array}{l}32(\text { rivaroxaban }=18, \\
\text { apixaban }=13\end{array}$ & $\begin{array}{l}\text { Ischemic cardiomyopathy } \\
\quad(58 \%)\end{array}$ & 12 & Not defined \\
\hline
\end{tabular}

Alizadeh (2019) ${ }^{19} \quad$ Prospective cohort

60 (VKA not specified)

38 (rivaroxaban $=22$, apixaban $=14$, edoxaban $=2)$ chemic cardiomyopathy apixaban $=13$, dabigatran $=1$ )

Non-ischemic cardiomyopathy $(23 \%)$ Acute MI (15\%)

Takotsubo cardiomyopathy (3\%)

Acute MI (100\%)

Bass $(2021)^{22} \quad$ Retrospective cohort

769 (all warfarin)

$180($ rivaroxaban $=77$, apixaban $=79$,

14 (DOAC not specified)

Not specified

Acute MI (48\%)

59 (all warfarin)
Acute MI or ischemic cardiomyopathy $(37.3 \%)$

Acute MI (47\%)

Non-ischemic cardiomyopathy $(40 \%)$

Ischemic heart disease $(13 \%)$

All patients post-acute MI or

heart failure with reduced ejection fraction
Unknown
Bleeding: Major bleeding, including intracranial bleed, major gastrointestinal bleed, and bleed requiring hospital admission

LV thrombus resolution: Determined by echocardiography or CMR Stroke: Thromboembolic stroke Bleeding: GUSTO criteria

Stroke: Clinically documented Bleeding: Minimal, minor and major bleeding according to TIMI

LV thrombus resolution: Determined by TTE with contrast

LV thrombus resolution: Determined by TTE

Bleeding: Major bleeding LV thrombus resolution: Determined by echocardiography

LV thrombus resolution:

Determined by

echocardiography and

complemented by CMR when needed 


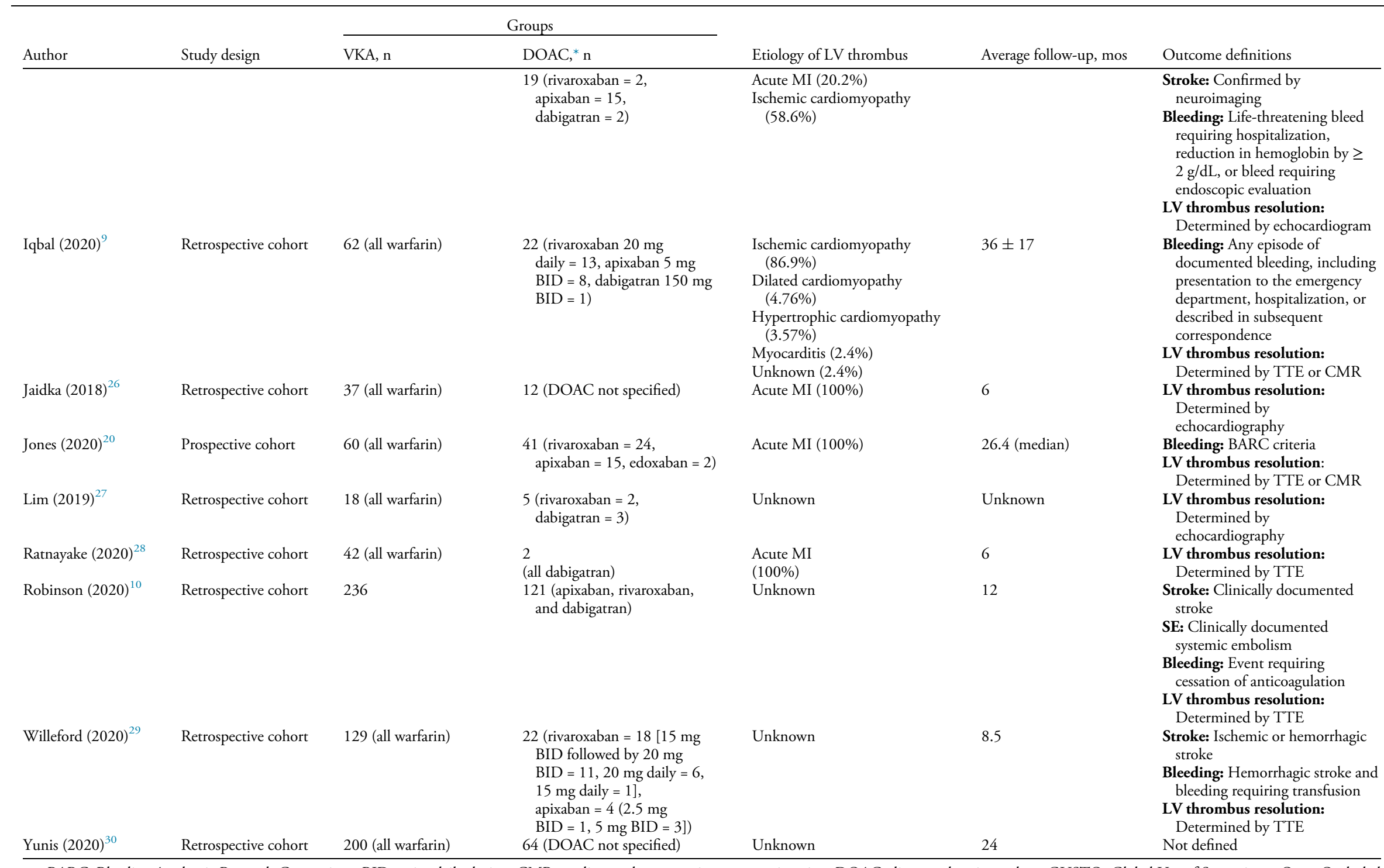

BARC, Bleeding Academic Research Consortium; BID, twice daily dosing; CMR, cardiovascular magnetic resonance imaging; DOAC, direct oral anticoagulant; GUSTO, Global Use of Strategies to Open Occluded

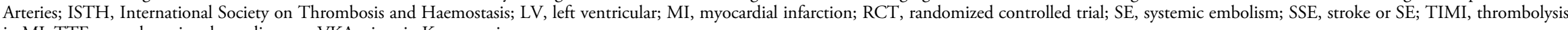
in MI; TTE, transthoracic echocardiogram; VKA, vitamin K antagonist.

"DOAC type and doses are provided where specified by the primary study. 


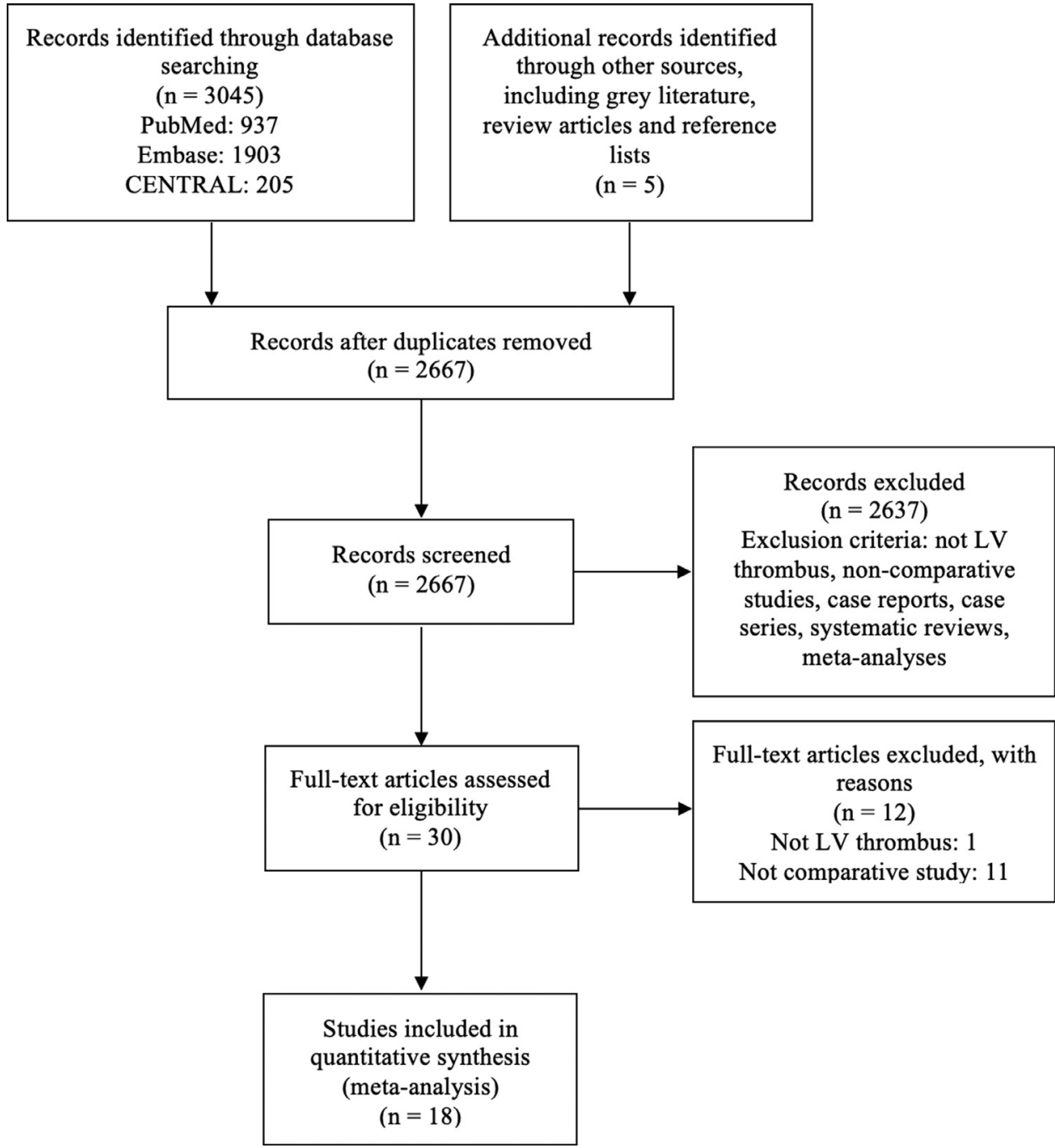

Figure 1. Preferred Reporting Items for Systematic Reviews and Meta-Analyses (PRISMA) flow diagram of literature search and study selection. LV, left ventricular.

studies met inclusion criteria and were included in this metaanalysis. Figure 1 summarizes the literature search and study selection according to the Preferred Reporting Items for Systematic Reviews and Meta-Analyses (PRISMA) standards.

We included 2 RCTs, ${ }^{1,18} 2$ prospective cohort studies, ${ }^{19,20}$ and 14 retrospective cohort studies. ${ }^{7-10,21-30}$ One of the RCTs was limited to data presented at a conference, ${ }^{17}$ and 7 other studies were abstracts. ${ }^{18,19,24-27,30}$ The follow-up ranged from 3 months to 36 months. Studies had variable definitions of outcomes, summarized in Table 1. Stroke was reported in 10 studies, ${ }^{7-9,17,18,20-22,29,30}$ and bleeding in 13 studies. $^{\text {7-10,17-19,20,22,24,26,29,30 }}$

The risk of bias assessment was affected by the limited information provided in abstracts. The quality of cohort studies was assessed using the Newcastle-Ottawa Scale, with which a study can be awarded a maximum of 9 points (Table 2). ${ }^{11}$ Eleven of 18 studies, 6 of which were abstracts, received 6 or fewer points. ${ }^{7,19,21-27,28,30}$ The quality of RCTs was assessed using the Cochrane risk-of-bias 2 tool (Fig. 2). ${ }^{12}$ As the 2 RCTs were not available in full text form, they were judged to have some concerns for multiple domains. ${ }^{17,18}$

\section{Baseline characteristics of patients}

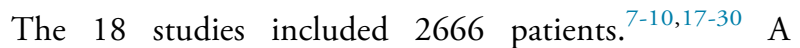
DOAC (rivaroxaban, apixaban, edoxaban, or dabigatran) was used in 674 patients. A VKA (warfarin, acenocoumarol, or fluindione) was used in 1992 patients. Baseline characteristics of patients included in each primary study are summarized in Supplemental Table S1. Of note, the population was relatively young, with a mean age between 49.1 years and 63.4 years. Additionally, edoxaban was used in only 2 studies. ${ }^{19,20}$ 
Table 2. Risk of bias assessment of cohort studies

\begin{tabular}{|c|c|c|c|c|c|c|c|c|}
\hline \multirow[b]{2}{*}{ Study } & \multicolumn{4}{|c|}{ Selection } & \multirow[b]{2}{*}{$\begin{array}{l}\text { Comparability } \\
\text { Comparability of } \\
\text { cohorts on the basis } \\
\text { of the design or } \\
\text { analysis }\end{array}$} & \multicolumn{3}{|c|}{ Outcome } \\
\hline & $\begin{array}{l}\text { Representativeness } \\
\text { of the exposed } \\
\text { cohort }\end{array}$ & $\begin{array}{l}\text { Selection of the } \\
\text { non-exposed } \\
\text { cohort }\end{array}$ & $\begin{array}{l}\text { Ascertainment of } \\
\text { exposure }\end{array}$ & $\begin{array}{l}\text { Demonstration } \\
\text { that outcome of } \\
\text { interest was not } \\
\text { present at start of } \\
\text { study }\end{array}$ & & $\begin{array}{l}\text { Assessment of } \\
\text { outcome }\end{array}$ & $\begin{array}{l}\text { Length of follow- } \\
\text { up sufficient for } \\
\text { outcomes to occur }\end{array}$ & $\begin{array}{l}\text { Adequacy of } \\
\text { follow-up of } \\
\text { cohorts }\end{array}$ \\
\hline Ali $(2020)^{21}$ & * & $*$ & $*$ & $*$ & & $*$ & $*$ & \\
\hline Alizadeh $(2019)^{19}$ & & * & * & * & & * & * & \\
\hline Bass $(2021)^{22}$ & * & * & * & * & & * & & \\
\hline Cochran $(2021)^{7}$ & * & * & * & * & & * & * & \\
\hline Daher $(2020)^{23}$ & * & * & * & * & & * & & \\
\hline Durrer-Ariyakuddy (2019) ${ }^{24}$ & & * & * & * & & * & * & \\
\hline $\operatorname{Gama}(2019)^{25}$ & & * & * & * & & * & & * \\
\hline Guddeti $(2020)^{8}$ & * & * & * & * & & * & * & * \\
\hline Igbal $(2020)^{9}$ & * & * & * & * & & * & * & * \\
\hline Jaidka $(2018)^{26}$ & * & * & * & * & & * & * & \\
\hline Jones $(2020)^{20}$ & * & * & * & * & ** & * & * & * \\
\hline $\operatorname{Lim}(2019)^{27}$ & & * & * & * & & * & & \\
\hline Ratnayake $(2020)^{28}$ & & * & * & * & & * & * & * \\
\hline Robinson $(2020)^{10}$ & * & * & * & * & ** & * & * & \\
\hline Willeford $(2020)^{29}$ & * & * & * & * & ** & * & * & \\
\hline Yunis $(2020)^{30}$ & & * & * & * & & * & * & \\
\hline
\end{tabular}

Asterisks $(*)$ indicate the star rating according to the Newcastle-Ottawa Scale for cohort studies. A study can be awarded a maximum of 4 stars for selection, 2 stars for comparability, and 3 stars for outcome. 


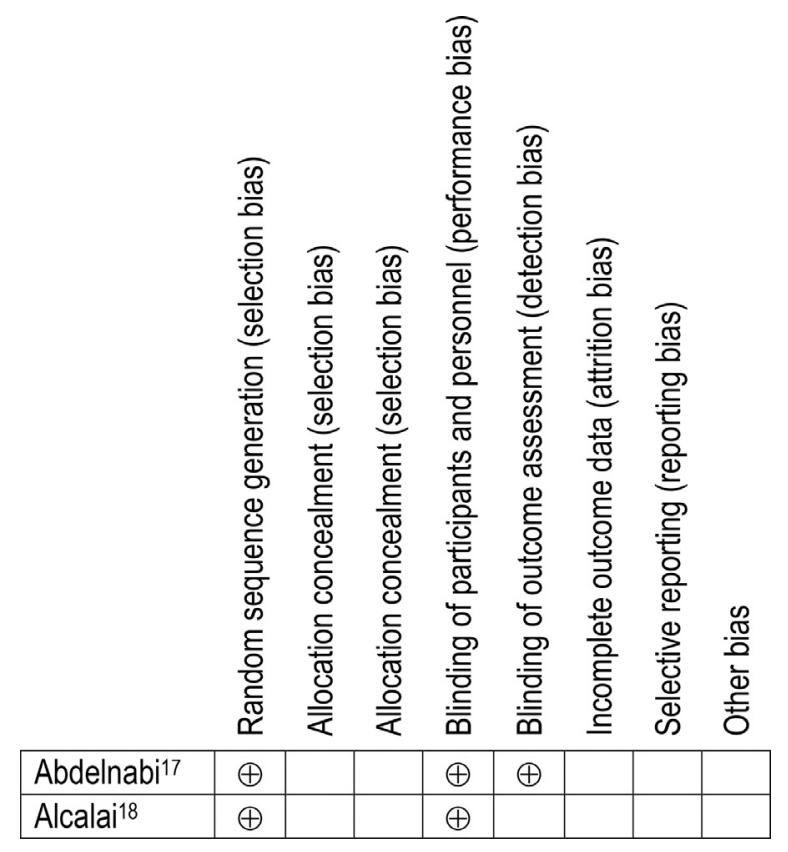

Figure 2. Risk of bias assessment of randomized controlled trials. Risk of bias assessment for randomized controlled trials is based on the Cochrane risk-of-bias 2 tool. $\oplus$ indicates that the study has met the domain criterion; an empty cell indicates that it is unclear whether the domain criterion has been met.

\section{Outcomes}

Primary outcomes. Stroke occurred in $6.0 \%$ of patients treated with DOACs and $10.8 \%$ of patients treated with VKAs. In comparison to VKAs, there was a statistically significant reduction in stroke among those treated with DOACs (OR 0.63, 95\% CI 0.42-0.96; $P=0.03 ; I^{2}=0 \%$; Fig. 3). Bleeding occurred in $7.0 \%$ of patients on DOACs and $9.7 \%$ of patients on VKAs. Although the point estimate favoured DOACs, the difference was not statistically significant (OR 0.72 , 95\% CI $0.50-1.02 ; P=0.07 ; I^{2}=0 \%$; Fig. 4 ).
Secondary outcomes. Comparisons of DOACs to VKAs revealed no significant differences in SE (6.7\% vs $10.7 \%$; OR $0.77,95 \%$ CI $0.41-1.44 ; P=0.41 ; I^{2}=0 \%$; Fig. 5), SSE (16.8\% vs $22.2 \%$; OR 0.83 , 95\% CI $0.53-1.33$; $P=0.45$; $I^{2}=33 \%$; Fig. 6), mortality (12.8\% vs $13.3 \%$; OR 1.01 , 95\% CI $0.64-1.57 ; P=0.98 ; I^{2}=0 \%$; Fig. 7 ), or LV thrombus resolution $(69.3 \%$ vs $69.6 \%$; OR 1.29 , 95\% CI 0.83 1.99; $P=0.26 ; I^{2}=56 \%$; Fig. 8). Primary and secondary outcomes are summarized in Supplemental Table S2.

\section{Sensitivity analysis}

A sensitivity analysis was conducted for the primary outcomes to explore the impact of excluding abstracts. Stroke remained statistically significant $(P=0.03)$, and the point estimate further favoured DOACs (OR 0.57, 95\% CI 0.35-0.95; $I^{2}=0 \%$; Supplemental Fig. S3)..$^{7-9,20-22,29}$ Similarly for bleeding, the point estimate further favoured DOACs (OR 0.67, 95\% CI $\left.0.45-1.00 ; I^{2}=0 \%\right)$, and the $P$-value was reduced to 0.05 (Supplemental Fig. S4). ${ }^{\text {7-10,20,22,29 }}$

\section{Narrative synthesis}

Primary outcomes. Ten of the included studies reported on the primary outcome of stroke. Two of these studies were RCTs. ${ }^{7-9,17,18,20-22,29,30}$ One of the RCTs reported no stroke in the DOAC and VKA groups, but this study included only 25 participants, and follow-up was limited to 3 months. ${ }^{18}$ The second RCT demonstrated significantly fewer strokes over 6 months in those treated with rivaroxaban compared to VKA ( $0 \%$ vs $10 \%, P=0.04) .{ }^{17}$ The remaining 8 cohort studies all demonstrated numerically higher but not statistically significant rates of stroke in the VKA group. $7-9,20-22,29,30$

Bleeding was examined in 13 studies, including 2 RCTs and one prospective cohort study. ${ }^{7-10,17-20,22,24,26,29,30}$ Eleven studies reported similar bleeding events in the DOAC and VKA groups. ${ }^{7-10,17,18,22,24,26,29,30}$ Two studies, by Alizadeh et al. ${ }^{19}$ and Jones et al., ${ }^{20}$ found an increased number of major bleeding events in patients receiving VKAs $(P=0.03)$. Jones et al. found that most of these bleeding events occurred in the context of triple or dual antiplatelet therapy and included

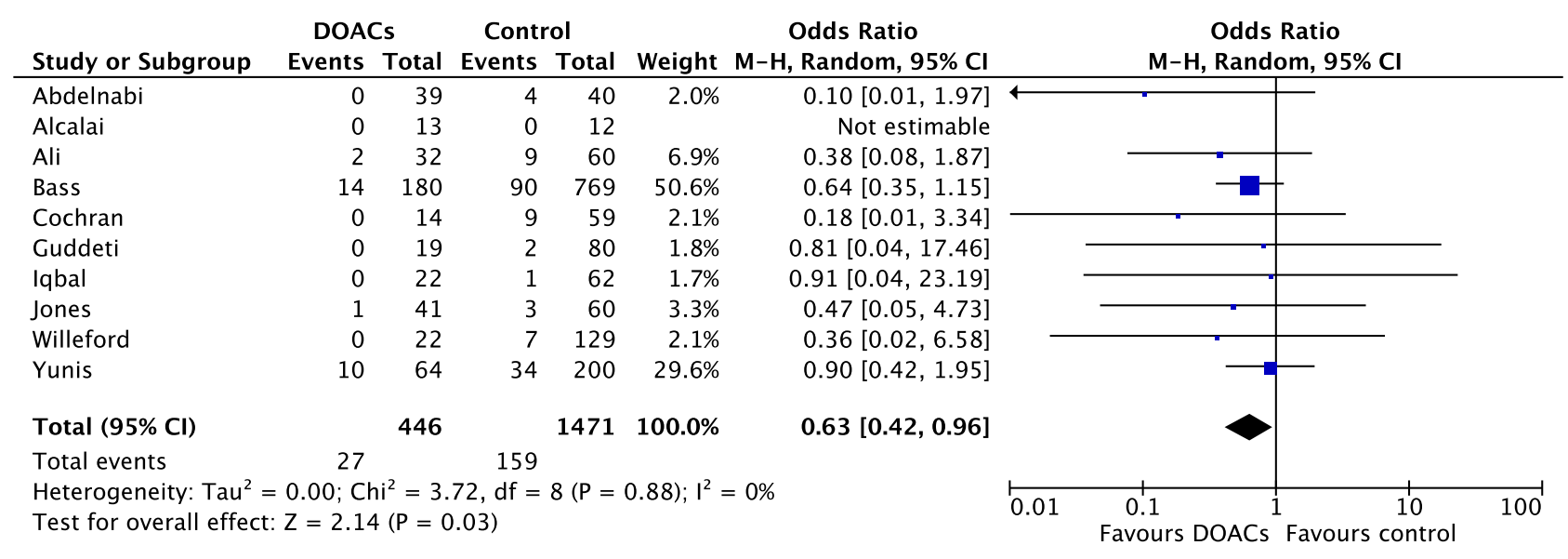

Figure 3. Forest plot of the individual and combined rates of stroke. CI, confidence interval; df, degrees of freedom; DOACs, direct oral anticoagulants; M-H, Mantel-Haenszel. 


\begin{tabular}{|c|c|c|c|c|c|c|c|c|c|c|}
\hline Study or Subgroup & \multicolumn{2}{|c|}{ DOACs } & Control & $\begin{array}{l}\text { ol } \\
\text { Total }\end{array}$ & Weight & \multirow{2}{*}{$\begin{array}{c}\begin{array}{c}\text { Odds Ratio } \\
\text { M-H, Random, 95\% Cl }\end{array} \\
0.31[0.06,1.62]\end{array}$} & \multicolumn{4}{|c|}{$\begin{array}{l}\text { Odds Ratio } \\
\text { M-H, Random, } 95 \% \mathrm{Cl}\end{array}$} \\
\hline Abdelnabi & 2 & 39 & 6 & 40 & $4.6 \%$ & & & & $F$ & \\
\hline Alcalai & 0 & 13 & 2 & 12 & $1.3 \%$ & $0.16[0.01,3.60]$ & & & & \\
\hline Alizadeh & 0 & 38 & 3 & 60 & $1.4 \%$ & $0.21[0.01,4.25]$ & & & & \\
\hline Bass & 14 & 180 & 84 & 769 & $36.5 \%$ & $0.69[0.38,1.24]$ & & $\rightarrow$ & - & \\
\hline Cochran & 2 & 14 & 8 & 59 & $4.6 \%$ & $1.06[0.20,5.66]$ & & & & \\
\hline Durrer-Ariyakuddy & 0 & 20 & 0 & 33 & & Not estimable & & & & \\
\hline Guddeti & 1 & 19 & 4 & 80 & $2.5 \%$ & $1.06[0.11,10.02]$ & & & & \\
\hline lqbal & 0 & 22 & 6 & 62 & $1.5 \%$ & $0.19[0.01,3.57]$ & & & & \\
\hline Jaidka & 3 & 12 & 6 & 37 & $5.2 \%$ & $1.72[0.36,8.30]$ & & & & \\
\hline Jones & 6 & 41 & 19 & 60 & $12.2 \%$ & $0.37[0.13,1.03]$ & & & & \\
\hline Robinson & 8 & 121 & 19 & 236 & $17.4 \%$ & $0.81[0.34,1.90]$ & & & & \\
\hline Willeford & 1 & 22 & 5 & 129 & $2.6 \%$ & $1.18[0.13,10.62]$ & & & & \\
\hline Yunis & 5 & 64 & 10 & 200 & $10.3 \%$ & $1.61[0.53,4.90]$ & & & & \\
\hline Total $(95 \% \mathrm{Cl})$ & & 605 & & 1777 & $100.0 \%$ & $0.72[0.50,1.02]$ & & & & \\
\hline Total events & 42 & & 172 & & & & & & & \\
\hline $\begin{array}{l}\text { Heterogeneity: } \mathrm{Tau}^{2} \\
\text { Test for overall effec }\end{array}$ & $\begin{array}{l}0.00 ; C h \\
Z=1.83\end{array}$ & $\begin{array}{l}i^{2}=8 \\
(P=0\end{array}$ & $\begin{array}{l}85, \mathrm{df}= \\
.07)\end{array}$ & $11(\mathrm{P}$ & $0.64) ; 1^{2}$ & $=0 \%$ & 0.01 & $\begin{array}{cc}0.1 & 1 \\
\text { Favours DOACs }\end{array}$ & Favours cor & $\begin{array}{l}10 \\
\text { ontrol }\end{array}$ \\
\hline
\end{tabular}

Figure 4. Forest plot of the individual and combined rates of bleeding. $\mathrm{Cl}$, confidence interval; df, degrees of freedom; DOACs, direct oral anticoagulants; M-H, Mantel-Haenszel.

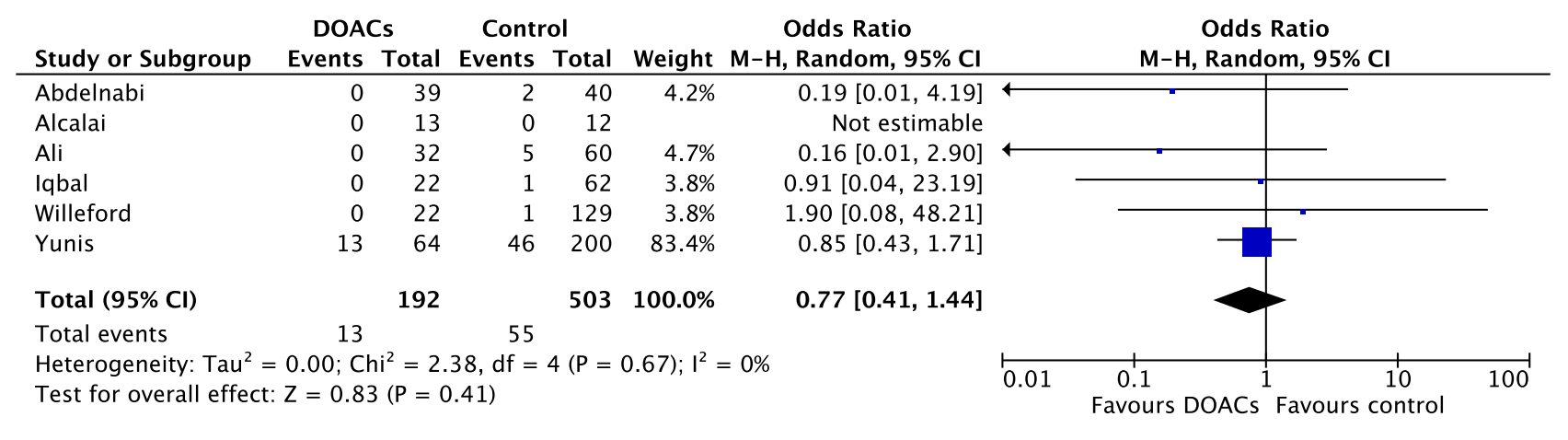

Figure 5. Forest plot of the individual and combined rates of systemic embolism. Cl, confidence interval; df, degrees of freedom; DOACs, direct oral anticoagulants; M-H, Mantel-Haenszel.

\begin{tabular}{|c|c|c|c|c|c|c|c|c|c|c|}
\hline Study or Subgroup & \multicolumn{2}{|c|}{ DOACs } & Control & $\begin{array}{l}\text { ol } \\
\text { Total }\end{array}$ & Weight & $\begin{array}{c}\text { Odds Ratio } \\
\text { M-H, Random, } 95 \% \mathrm{Cl} \\
\end{array}$ & \multicolumn{4}{|c|}{$\begin{array}{c}\text { Odds Ratio } \\
\text { M-H, Random, } 95 \% \mathrm{Cl}\end{array}$} \\
\hline Abdelnabi & 0 & 39 & 6 & 40 & $2.4 \%$ & $0.07[0.00,1.24]$ & & & & \\
\hline Alcalai & 0 & 13 & 0 & 12 & & Not estimable & & & & \\
\hline Ali & 2 & 32 & 14 & 60 & $7.1 \%$ & $0.22[0.05,1.03]$ & & & & \\
\hline Bass & 55 & 180 & 254 & 769 & $29.2 \%$ & $0.89[0.63,1.27]$ & & & & \\
\hline Cochran & 0 & 14 & 9 & 59 & $2.4 \%$ & $0.18[0.01,3.34]$ & & & & \\
\hline Daher & 2 & 17 & 4 & 42 & $5.6 \%$ & $1.27[0.21,7.66]$ & & & & \\
\hline Guddeti & 0 & 19 & 2 & 80 & $2.1 \%$ & $0.81[0.04,17.46]$ & & & & \\
\hline lqbal & 0 & 22 & 2 & 62 & $2.1 \%$ & $0.54[0.02,11.64]$ & & & & \\
\hline Jaidka & 0 & 12 & 2 & 37 & $2.1 \%$ & $0.57[0.03,12.66]$ & & & & \\
\hline Jones & 1 & 41 & 3 & 60 & $3.6 \%$ & $0.47[0.05,4.73]$ & & & & \\
\hline Robinson & 17 & 121 & 14 & 236 & $18.4 \%$ & $2.59[1.23,5.46]$ & & & $\longrightarrow$ & \\
\hline Willeford & 0 & 22 & 8 & 129 & $2.4 \%$ & $0.32[0.02,5.70]$ & & & & \\
\hline Yunis & 23 & 64 & 80 & 200 & $22.5 \%$ & $0.84[0.47,1.51]$ & & & & \\
\hline Total $(95 \% \mathrm{Cl})$ & & 596 & & 1786 & $100.0 \%$ & $0.83[0.53,1.33]$ & & & & \\
\hline Total events & 100 & & 398 & & & & & & & \\
\hline $\begin{array}{l}\text { Heterogeneity: } \text { Tau }^{2} \\
\text { Test for overall effec }\end{array}$ & $\begin{array}{l}0.16 ; C h \\
Z=0.76\end{array}$ & $\begin{array}{l}\mathrm{i}^{2}=16 \\
(\mathrm{P}=0\end{array}$ & $\begin{array}{l}5.54, \mathrm{df}= \\
.45)\end{array}$ & $=11(\mathrm{P}$ & $=0.12)$ & $1^{2}=33 \%$ & 0.01 & $\begin{array}{cc}0.1 & 1 \\
\text { Favours DOACs } & \end{array}$ & $\begin{array}{r}1 \\
\text { Favours co }\end{array}$ & $\begin{array}{l}10 \\
\text { ontrol }\end{array}$ \\
\hline
\end{tabular}

Figure 6. Forest plot of the individual and combined rates of composite stroke or systemic embolism. Cl, confidence interval; df, degrees of freedom; DOACs, direct oral anticoagulants; M-H, Mantel-Haenszel. 
Odds Ratio

DOACs Control

Events Total Events Total Weight $\mathrm{M}-\mathrm{H}$, Random, $95 \% \mathrm{CI}$

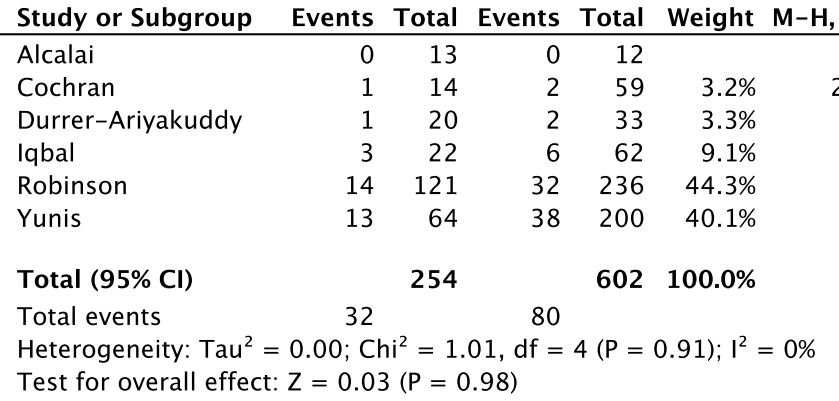

Not estimable

$2.19[0.18,26.05]$

$0.82[0.07,9.62]$

$1.47[0.34,6.48]$

$0.83[0.43,1.63]$

$1.09[0.54,2.20]$

$1.01[0.64,1.57]$

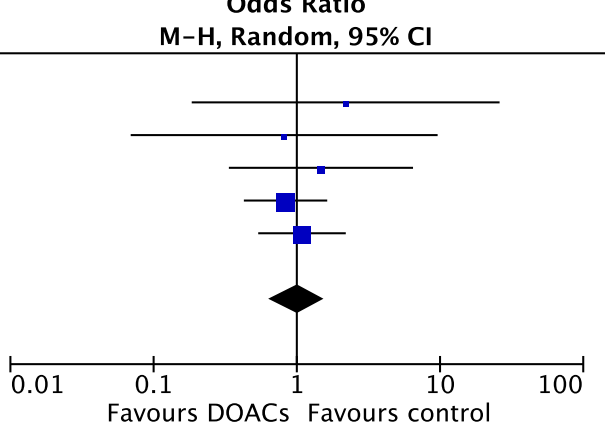

Figure 7. Forest plot of the individual and combined rates of mortality. $\mathrm{Cl}$, confidence interval; df, degrees of freedom; DOACs, direct oral anticoagulants; M-H, Mantel-Haenszel.

\begin{tabular}{|c|c|c|c|c|c|c|c|c|c|}
\hline Study or Subgroup & \multicolumn{2}{|c|}{ DOACs } & \multicolumn{2}{|c|}{ Control } & Weight & $\begin{array}{c}\text { Odds Ratio } \\
\text { M-H, Random, 95\% Cl }\end{array}$ & \multicolumn{3}{|c|}{$\begin{array}{c}\text { Odds Ratio } \\
\text { M-H, Random, } 95 \% \mathrm{CI}\end{array}$} \\
\hline Abdelnabi & 34 & 39 & 32 & 40 & $6.3 \%$ & $1.70[0.50,5.74]$ & & & \\
\hline Alcalai & 12 & 13 & 12 & 12 & $1.5 \%$ & $0.33[0.01,8.99]$ & & & \\
\hline Ali & 18 & 32 & 37 & 60 & $8.4 \%$ & $0.80[0.33,1.91]$ & & $\cdot$ & \\
\hline Alizadeh & 29 & 38 & 32 & 60 & $8.2 \%$ & $2.82[1.14,6.96]$ & & & \\
\hline Cochran & 11 & 14 & 12 & 59 & $5.4 \%$ & $14.36[3.45,59.73]$ & & & \\
\hline Daher & 12 & 17 & 30 & 42 & $6.2 \%$ & $0.96[0.28,3.32]$ & & & \\
\hline Durrer-Ariyakuddy & 9 & 20 & 19 & 33 & $6.9 \%$ & $0.60[0.20,1.85]$ & & & \\
\hline Gama & 11 & 13 & 31 & 53 & $4.6 \%$ & $3.90[0.79,19.38]$ & & & \\
\hline Guddeti & 15 & 19 & 65 & 80 & $6.2 \%$ & $0.87[0.25,2.98]$ & & & \\
\hline lqbal & 13 & 22 & 42 & 62 & $7.5 \%$ & $0.69[0.25,1.88]$ & & $\sigma$ & \\
\hline Jaidka & 8 & 12 & 18 & 37 & $5.6 \%$ & $2.11[0.54,8.25]$ & & & \\
\hline Jones & 34 & 41 & 39 & 60 & $7.7 \%$ & $2.62[0.99,6.91]$ & & & \\
\hline Lim & 1 & 5 & 3 & 18 & $2.4 \%$ & $1.25[0.10,15.50]$ & & & \\
\hline Ratnayake & 1 & 2 & 34 & 42 & $1.9 \%$ & $0.24[0.01,4.18]$ & & & \\
\hline Robinson & 56 & 121 & 131 & 236 & $11.2 \%$ & $0.69[0.44,1.07]$ & & & \\
\hline Willeford & 13 & 22 & 63 & 129 & $8.1 \%$ & $1.51[0.60,3.79]$ & & & \\
\hline Yunis & 62 & 64 & 200 & 200 & $1.8 \%$ & $0.06[0.00,1.32]$ & $\longleftarrow$ & & \\
\hline Total $(95 \% \mathrm{CI})$ & & 494 & & 1223 & $100.0 \%$ & $1.29[0.83,1.99]$ & & & \\
\hline Total events & 339 & & 800 & & & & & & \\
\hline $\begin{array}{l}\text { Heterogeneity: } \mathrm{Tau}^{2} \\
\text { Test for overall effec }\end{array}$ & $0.39 ; \mathrm{Ch}$ & $\begin{array}{l}h^{2}=35 \\
(P=0\end{array}$ & $5.96, \mathrm{df}=$ & $=16(P$ & $=0.003) ;$ & $; I^{2}=56 \%$ & 0.01 & $\begin{array}{ll}1 \\
0.1\end{array}$ & Favours co \\
\hline
\end{tabular}

Figure 8. Forest plot of the individual and combined rates of left ventricular (LV) thrombus resolution. Cl, confidence interval; df, degrees of freedom; DOACs, direct oral anticoagulants; M-H, Mantel-Haenszel.

gastrointestinal bleeding, subarachnoid hemorrhage, and epistaxis requiring hospital admission. ${ }^{20}$ In the remaining studies, there was no significant difference in total bleeding events among patients receiving DOACs vs VKAs. ${ }^{7-}$ 10,17,18,22,24,26,29,30 Two studies additionally examined rates of blood product administration. ${ }^{22,29}$ Willeford et al. found no difference in blood product administration between DOACs and VKAs (4.5\% vs 3.1\%, $P=1.0) .{ }^{29}$ A larger study by Bass et al. reported more blood product administration among patients on warfarin compared to those taking a DOAC (25.8\% vs $13.9 \%, P<0.001){ }^{22}$

Secondary outcomes. Six studies looked at the outcome of SE, including 2 preliminary RCTs and 4 retrospective observational studies. ${ }^{9,17,18,21,29,30}$ In the RCT by Alcalai et al., no patients developed SE in either group after 3 months of follow-up. ${ }^{18}$ In all other studies, there was no significant difference in SE between the DOAC and VKA groups, although overall event rates were quite low across the studies. 9, 17,21,29,30

The composite secondary outcome of SSE was reported in 13 studies. $^{-10,17,18,20-23,26,29,30}$ In the multicenter cohort study by Robinson et al., higher hazards of SSE were observed in those treated with DOACs alone (HR 2.88, 95\% CI 1.226.80; $P=0.02) .{ }^{10}$ However, a recently published retrospective cohort study by Bass et al.- the largest to date, with 949 participants-found no difference in SSE between the DOAC and VKA groups (55 of $180(30.6 \%$ ) vs 254 of 769 (33\%), $P=0.53) .{ }^{22}$ Nine other studies also reported no difference in composite SSE events between DOACs and VKAs. ${ }^{7-9,18,20,23,26,29,30}$ Finally, an RCT by Abdelnabi et al., and a retrospective cohort study by Ali et al., reported significantly fewer composite SSE events with DOACs compared to VKAs $(0 \%$ vs $15 \%[P=0.01]$ and $6 \%$ vs $23 \%[P=0.0001]$, respectively). ${ }^{17,21}$

Six studies reported on mortality. ${ }^{7,9,10,18,24,30}$ There were no deaths in the DOAC and VKA groups in the RCT by Alcalai et al., ${ }^{18}$ and all remaining studies found no significant difference in all-cause mortality between the 2 groups.

Seventeen studies reported on LV thrombus resolution. 7-10,17-21,23-30 Twelve studies reported no significant difference in LV thrombus resolution between DOACs and VKAs. $^{\text {7-10,18,23,24,26-30 }}$ Three studies ${ }^{19,20,25}$ reported 
significantly greater LV thrombus resolution with DOACs over the entire study period, and 2 other studies ${ }^{17,21}$ found initial resolution to be faster with DOACs, but no significant differences in resolution when measured over the entire study period. Jones et al. reported consistently higher LV thrombus resolution with DOACs compared with VKAs at different time points through the 1-year follow-up period $(82 \%$ vs $64.4 \%, P=0.0018$ ) even after adjusting for baseline variables (OR 1.8, 95\% CI 1.2-2.9). ${ }^{20} \mathrm{~A}$ similar finding was reported by Alizadeh et al., with LV thrombus resolution greater at 1 year with DOACs compared to VKAs $(75 \%$ vs $53 \%$, $P=0.0018$ ), an effect that persisted with adjustment for baseline variables (OR 1.8, 95\% CI 1.2-2.9). ${ }^{19}$ Finally, 2 studies noted faster thrombus resolution with the use of DOACs at 1 month follow-up, but the overall rates of thrombus resolution were similar between the 2 groups $(71.79 \%$ vs $47.5 \%$, $P=0.03$ in Abdelnabi et al. ${ }^{\mathrm{P}}$, and $34 \%$ vs $12 \%, P \leq$ 0.00001 in Ali et al. ${ }^{21}$ ).

\section{Discussion}

Our meta-analysis has shown the following: (i) There was a statistically significant decrease in stroke among those treated with DOACs compared to VKAs, without an increase in bleeding; and (ii) there were no significant differences in the secondary outcomes of SE, SSE, mortality, and LV thrombus resolution.

Current guidelines recommend the use of VKAs for treatment of LV thrombi to reduce the risk of stroke and systemic embolism. ${ }^{4,5}$ Given the preference for DOACs in atrial fibrillation, there is considerable interest in using these agents for other indications. DOACs offer numerous benefits over VKAs, including their ease of use, minimal need for monitoring, and fewer drug interactions. ${ }^{6}$ When studied in patients with atrial fibrillation, DOACs were associated with decreased SSE and all-cause mortality, with less major bleeding and intracranial hemorrhage compared to VKAs. ${ }^{6,31}$ Unfortunately, these findings have not been established in the LV thrombus population, and the risks and benefits of their use for this indication are unknown.

\section{Primary outcomes}

In this meta-analysis, DOAC use was associated with a $37 \%$ decrease in odds of stroke compared to VKA use (OR $0.63,95 \%$ CI $0.42-0.96 ; P=0.03 ; I^{2}=0 \%$ ). Ten studies, of which 3 were abstracts or conference proceedings, reported on stroke. ${ }^{7-9,17,18,20-22,29,30}$ Nine of these studies demonstrated increased stroke events in the VKA group. - $9,17,20-22,29,30^{-1}$ However, none reached statistical significance, likely owing to small sample size and overall low incidence of stroke during the follow-up period. One study reported no stroke in both the DOAC and VKA groups, but this study included only 25 participants, and follow-up was limited to 3 months. ${ }^{18}$ When a sensitivity analysis was performed by excluding the 3 abstracts/conference proceedings, there was still a significant reduction in odds of stroke with DOACs, supporting the original analysis $(\mathrm{OR} 0.57,95 \%$ CI $0.35-0.95 ; P=0.03$, $\left.I^{2}=0 \%\right)^{7-9,20-22,29}$ It is interesting that RCTs comparing DOACs to warfarin in atrial fibrillation have found no significant difference in the risk of ischemic stroke, whereas our meta-analysis suggests a possible reduction in stroke with DOACs. ${ }^{31-33}$ This discrepancy may be attributable to differences in the underlying etiologies of atrial and ventricular thrombi. An LV thrombus is often due to a single insult of an acute MI, as was commonly seen in the included studies (Table 1)..$^{-3}$ This type of thrombus differs from a thrombus due to atrial fibrillation, which is an ongoing process rather than a single event. Therefore, it is possible that the risk of stroke due to an LV thrombus associated with a discrete MI is more easily modifiable than the risk of stroke due to an atrial thrombus, which is associated with an ongoing arrhythmia. Another important factor to consider when interpreting our results is time in therapeutic international normalized ratio (INR). Although these data were not consistently provided across studies, Ali et al. reported that $71 \%$ of patients who developed ischemic stroke on warfarin had a subtherapeutic INR. $^{21}$ Similarly, Jones et al. found that $35 \%$ of patients on VKAs had a subtherapeutic INR. ${ }^{20}$ Thus, it is unclear if the higher odds of stroke in those using VKAs are due to issues with compliance, maintenance of therapeutic INR, or inherent differences in the anticoagulants themselves. Previous meta-analyses have not examined stroke as an individual outcome, but rather a composite SSE, making this the first review to demonstrate this statistically significant difference. , $34-36^{-3}$ However, this finding must be contextualized by the limitations of the primary studies, including the inherent bias of cohort studies and the lack of an adjusted analysis. Further studies-ideally in the form of adequately powered RCTsare required to substantiate this finding.

Our second primary outcome was bleeding, which was reported in 13 studies. $10,17-19,20,22,24,26,29,30$ We found that there were fewer bleeding events in those on DOACs compared to those on VKAs, but this finding did not reach statistical significance $(7.0 \%$ vs $9.7 \%$; OR $0.72,95 \%$ CI $0.50-1.02$; $\left.P=0.07 ; I^{2}=0 \%\right)$. When a sensitivity analysis was performed, including data from only the 7 full-text articles, the point estimate for bleeding was further in favour of DOACs (OR 0.67, $95 \%$ CI $\left.\left.0.45-1.00 ; P=0.05 ; I^{2}=0 \%\right)\right)^{7-10,20,22,29}$ This finding is consistent with results of 11 of the 13 primary studies, which also found bleeding rates to be similar between the groups. $^{7-10,17,18,22,24,26,29,30}$ Interpretation of the bleeding data is impacted by the variable definitions of bleeding across studies (Table 1), which affects our ability to draw firm conclusions. First, for example, a number of primary studies focused on major bleeding, such as intracranial hemorrhage or bleeding with hemodynamic instability, whereas other studies measured less-severe bleeding events not requiring hospitalization or transfusion (Table 1). Future research with standardized bleeding definitions will better ascertain bleeding risk. Second, other risk factors for bleeding were not consistently reported across studies, such as concurrent antiplatelet therapy, chronic kidney disease, supratherapeutic INR, and use of high-risk medications, such as steroids and nonsteroidal antiinflammatory drugs. ${ }^{37}$ This consideration is critical, as many of the included patients developed LV thrombi following acute MIs, which typically require concomitant antiplatelet therapy. Iqbal et al. was one of 2 studies to examine bleeding rates among those on antiplatelet therapy, and they reported that half of the patients who had a significant bleed on VKA were receiving dual antiplatelet therapy. ${ }^{9,20}$ Finally, the type and dosage of DOAC prescribed was also inconsistently 
reported in studies and warrants further investigation. Large RCTs have demonstrated significant differences in bleeding with various DOAC regimens compared to VKAs in the atrial fibrillation population, and it is important to understand whether this relationship also exists in the LV thrombus population. $^{32,33,38}$

\section{Secondary outcomes}

We found no statistically significant differences between DOACs and VKAs across the secondary outcomes of SE, SSE, mortality, and LV thrombus resolution.

Six studies reported on SE and did not identify significant differences between those using DOACs vs VKAs (OR 0.77, 95\% CI $\left.0.41-1.44 ; P=0.41 ; I^{2}=0 \%\right)^{9,17,18,21,29,30}$ It is unclear how many of these SE events occurred in the context of a subtherapeutic INR or medication non-adherence, and whether there are differences between individual DOAC agents. No prior meta-analyses examined SE as an individual outcome; hence, SE is an area for future research.

A total of 13 studies measured stroke or SE that were combined into a composite SSE outcome. . $^{\text {10,17,18,20-23,26,29,30 }}$ The cohort study by Robinson et al.- - one of the largest conducted on this topic to date $(\mathrm{n}=514)$ - showed significantly more SSE events in the DOAC group (HR 2.88, 95\% CI 1.22-6.80; $P=0.02) .{ }^{10}$ However, a preliminary RCT by Abdelnabi et al. found fewer SSE events in those taking DOACs $(0 \%$ vs $15 \%, P=0.01)$, as did a retrospective study by Ali et al. $(6 \%$ vs $23 \%, P=0.0001) .{ }^{17,21}$ The remaining 10 primary studies found no statistically significant difference between DOACs and VKAs. ${ }^{7-9,18,20,22,23,26,29,30}$ Similarly, our pooled analysis also showed that DOACs and VKAs were comparable in terms of SSE (OR 0.83, 95\% CI 0.53-1.33; $\left.P=0.45 ; I^{2}=33 \%\right)$. Concerns about off-label DOAC use in LV thrombus have emerged since the Robinson et al. publication; however, in that study, there were a considerable number of patients who switched treatment groups $(n=52$ warfarin to DOAC, $\mathrm{n}=19$ DOAC to warfarin). ${ }^{10}$ When data analysis was limited to those who had received only warfarin or only DOACs, the possibility of a four-fold increase in hazards of SSE was identified, but the point estimate was no longer statistically significant (HR 1.99, 95\% CI 0.91-4.35; $P=0.08) .{ }^{10}$ Furthermore, RCT data by Abdelnabi et al. ${ }^{17}$ did not support the findings by Robinson et al., ${ }^{10}$ instead demonstrating decreased SSE with DOACs. However, this study was also limited by a small sample size and open-label design. Overall, our findings are in keeping with those of other metaanalyses, which have also shown no significant difference in SSE between DOACs and VKAs.

Mortality was reported in 6 of the 18 studies, and no study identified a meaningful difference between DOACs and VKAs. ${ }^{7,9,10,18,24,30}$ In a meta-analysis by Dalia et al., mortality was found to be $9 \%$ higher in patients receiving warfarin compared to those treated with DOACs (risk ratio 1.09, 95\% CI $0.70-1.70$ ), but the difference was not statistically significant. $^{36}$ This finding is in keeping with our results, which showed no significant mortality benefit with use of one anticoagulant over the other.

There were no significant differences in LV thrombus resolution between those treated with DOACs vs VKAs (OR 1.29, 95\% CI 0.83-1.99; $\left.P=0.26 ; I^{2}=56 \%\right)^{7-10,17-21,23-30}$
LV thrombus resolution was assessed at different time points in individual studies, ranging from 3 to 36 months, and this limits interpretation of the results. Although we did not examine time to LV thrombus resolution, Jones et al. identified a greater degree of LV thrombus resolution with DOACs over VKAs at 1 year $(81 \%$ vs $63 \%, P=0.0018)$, in addition to faster LV thrombus resolution with DOACs. ${ }^{20}$ Another primary study also reported significantly earlier thrombus resolution with DOACs at 1 month compared to VKAs $(34 \%$ vs $12 \%, P \leq 0.00001) .^{21}$ Further investigation of the time to thrombus resolution with DOACs vs VKAs, and the association with the risk of SSE, is an avenue for further research. However, an important point to note is that the assessment of LV thrombus resolution varied considerably across studies thereby limiting the conclusions that can be drawn. For example, different imaging modalities were used to assess for thrombus resolution. Most studies used transthoracic echocardiogram, and only 4 used cardiac magnetic resonance imaging, 9,19,20,25 which has greater sensitivity in identifying small thrombi. ${ }^{39}$ Furthermore, only one primary study ${ }^{7}$ specified the use of contrast, which is known to enhance thrombus detection. $^{40}$

\section{Strengths}

Our meta-analysis has a number of strengths. To the best of our knowledge, this is the largest systematic review and meta-analysis comparing DOACs to VKAs in the management of LV thrombi. Our study pooled data from 18 studies and 2666 participants, making this the most comprehensive review of the literature on this topic to date. Although previous reviews have included data from case reports and observational studies, ours is the first to include data from 2 RCTs. ${ }^{34-}$ 36,41 Additionally, previously published meta-analyses have examined fewer outcomes and focused on composite SSE. ${ }^{7,34-}$

${ }^{36}$ In contrast, our meta-analysis examined 6 different safety and efficacy outcomes, and assessed stroke and SE as individual outcomes in addition to the composite SSE that previous reviews have examined. By doing so, we are the first review to identify a statistically significant reduction in stroke with DOAC use.

\section{Limitations}

The limitations of our meta-analysis are largely related to the included studies. The majority of primary studies were cohort studies, which are inherently prone to bias, and adjusted events were not consistently reported. Thus, our meta-analysis is limited to the pooling of unadjusted event rates. In addition, of the 18 studies included in this paper, 8 were not full-text articles, and limited information was available to ascertain baseline characteristics of participants and critically appraise study quality. ${ }^{17-19,24-27,30}$ Although our review includes 2 RCTs, additional data from ongoing larger RCTs will aid in understanding the differences between DOACs and VKAs for this indication. ${ }^{42-44}$ Also, the length of follow-up and outcome definitions varied considerably across studies (Table 1), which affects the conclusions that can be drawn. Information on important variables was also limited, including the dose of DOAC used, time in therapeutic INR, and concurrent antiplatelet therapy. These factors have 
important implications regarding the primary and secondary outcomes studied. The lack of prospective registration was an additional limitation of our study. Lastly, the population studied was relatively young, with a mean age of 49-63 years (Supplemental Table S1). Therefore, the results may not be generalizable to older patients who tend to have higher risks of bleeding and thromboembolic events.

\section{Conclusion}

Within the context of low-quality evidence, this meta-analysis suggests that DOACs may be an alternative to VKAs in the treatment of LV thrombi. Although a statistically significant reduction in stroke with DOAC use was identified, these results must be interpreted within the limitations of the included studies. Further research through RCTs is required to definitively compare the agents.

\section{Funding Sources}

Mohammed Shurrab is supported by a Fellowship Award from the Canadian Institutes of Health Research (CIHR).

\section{Disclosures}

The authors have no conflicts of interest to disclose.

\section{References}

1. Osherov AB, Borovik-Raz M, Aronson D, et al. Incidence of early left ventricular thrombus after acute anterior wall myocardial infarction in the primary coronary intervention era. Am Heart J 2009;157:1074-80.

2. Solheim S, Seljeflot I, Lunde K, et al. Frequency of left ventricular thrombus in patients with anterior wall acute myocardial infarction treated with percutaneous coronary intervention and dual antiplatelet therapy. Am J Cardiol 2010;106:1197-200.

3. Kernan WN, Ovbiagele B, Black HR, et al. Guidelines for the prevention of stroke in patients with stroke and transient ischemic attack: a guideline for healthcare professionals from the American Heart Association/American Stroke Association. Stroke 2014;45:2160-236.

4. Steg PG, James SK. Task Force on the Management of ST-Segment Elevation Acute Myocardial Infarction of the European Society of Cardiology (ESC), et al. ESC guidelines for the management of acute myocardial infarction in patients presenting with ST-segment elevation. Eur Heart J 2012;33:2569-619.

5. O'Gara PT, Kushner FG, Ascheim DD, et al. 2013 ACCF/AHA guideline for the management of ST-elevation myocardial infarction: a report of the American College of Cardiology Foundation/American Heart Association Task Force on Practice Guidelines. Circulation 2013;127: e362- 425 .

6. Ruff CT, Giugliano RP, Braunwald E, et al. Comparison of the efficacy and safety of new oral anticoagulants with warfarin in patients with atrial fibrillation: a meta-analysis of randomised trials. Lancet 2014;383:95562.

7. Cochran JM, Jia X, Kaczmarek J, et al. Direct oral anticoagulants in the treatment of left ventricular thrombus: a retrospective, multicenter study and meta-analysis of existing data. J Cardiovasc Pharmacol Ther 2021;26:173-8.

8. Guddeti R, Anwar M, Walters RW, et al. Treatment of left ventricular thrombus with direct oral anticoagulants: a retrospective observational study. Am J Med 2020;133:1488-91.
9. Iqbal H, Straw S, Craven TP, et al. Direct oral anticoagulants compared to vitamin $\mathrm{K}$ antagonist for the management of left ventricular thrombus. ESC Heart Fail 2020;7:2032-41.

10. Robinson AA, Trankle CR, Eubanks G, et al. Off-label use of direct oral anticoagulants compared with warfarin for left ventricular thrombi. JAMA Cardiol 2020;5:685-92.

11. Ottawa Hospital Research Institute. Available at: http://www.ohri.ca/ programs/clinical_epidemiology/oxford.asp. Accessed January 17, 2021.

12. Sterne JAC, Savović J, Page MJ, et al. RoB 2: a revised tool for assessing risk of bias in randomised trials. BMJ 2019;366:14898.

13. Shurrab M, Danon A, Alnasser S, et al. Dual-antithrombotic therapy with DOACs after acute coronary syndrome or percutaneous coronary intervention in atrial fibrillation: a meta-analysis of randomized controlled trials. Can J Cardiol 2020;36:135-42.

14. DerSimonian R, Laird N. Meta-analysis in clinical trials. Control Clin Trials 1986;7:177-88.

15. Higgins J, Green S. Cochrane Handbook for Systematic Reviews of Interventions. Version 5.1.0.

16. Moher D, Liberati A, Tetzlaff J, Altman DG, Group PRISMA. Preferred reporting items for systematic reviews and meta-analyses: the PRISMA statement. Ann Intern Med 2009;151:264-9.

17. Abdelnabi M, Saleh Y, Fareed A, et al. Comparative study of oral anticoagulation in left ventricular thrombi (No-LVT trial). Available at: https://www.acc.org/clinical-topics/ /media/14EDFF5E70174CC49959724AB9B68EFC.pdf. Accessed February 4, 2021.

18. Alcalai R, Rashad R, Butnaru A, Moravsky G, Leibowitz D. Apixaban versus warfarin in patients with left ventricular (LV) thrombus, a prospective randomized trial. Eur Heart J 2020;41:1545.

19. Alizadeh M, Antoniou S, Fhadil S, et al. The use of direct oral anti-coagulations (DOACs) compared to vitamin $\mathrm{K}$ antagonist in patients with left ventricular thrombus after acute myocardial infarction. Eur Heart J 2019; $40: 4026$.

20. Jones D, Wright P, Alizadeh M, et al. The use of novel oral anticoagulants compared to vitamin $\mathrm{K}$ antagonists (warfarin) in patients with left ventricular thrombus after acute myocardial infarction (AMI). Eur Heart J Cardiovasc Pharmacother 2020:pvaa096.

21. Ali Z, Isom N, Dalia T, et al. Direct oral anticoagulant use in left ventricular thrombus. Thromb J 2020;18:29.

22. Bass ME, Kiser TH, Page 2nd RL, et al. Comparative effectiveness of direct oral anticoagulants and warfarin for the treatment of left ventricular thrombus [e-pub ahead of print]. J Thromb Thrombolysis 2021. https://doi.org/10.1007/s11239-020-02371-6, accessed August 9, 2021.

23. Daher J, Costa A, Hilaire C, et al. Management of left ventricular thrombi with direct oral anticoagulants: retrospective comparative study with vitamin K antagonists. Clin Drug Investig 2020;40:343-53.

24. Durrer-Ariyakuddy K, Moccetti F, Stämpfli SF, et al. Direct oral anticoagulants versus vitamin $\mathrm{K}$-antagonists for treatment of left ventricular thrombus — insights from multicenter registry. Cardiovasc Med 2019;22:w02052.

25. Gama F, Freitas P, Trabulo M, et al. Direct oral anticoagulants are an effective therapy for left ventricular thrombus formation. Eur Heart J 2019; $40: 166$.

26. Jaidka A, Zhu T, Lavi S, Johri A. Treatment of left ventricular thrombus using warfarin versus direct oral anticoagulants following anterior myocardial infarction. Can J Cardiol 2018;34:S143.

27. Lim CW, Mamat RM, Hishammudin IA. Left ventricular thrombus: patient characteristics and treatment from a single tertiary centre's experience. Int J Cardiol 2019;297:20-1. 
28. Ratnayake C, Liu B, Benatar J, Stewart RAH, Somaratne JB. Left ventricular thrombus after ST segment elevation myocardial infarction: a single-centre observational study. N Z Med J 2020;133:45-54.

29. Willeford A, Zhu W, Stevens C, Thomas IC. Direct oral anticoagulants versus warfarin in the treatment of left ventricular thrombus. Ann Pharmacother 2021;55:839-45.

30. Yunis A, Seese L, Stearns B, et al. Direct oral anticoagulants are effective therapy in treating left ventricular thrombi. J Am Coll Cardiol 2020;75:948.

31. Andrade JG, Aguilar M, Atzema C, et al. The 2020 Canadian Cardiovascular Society/Canadian Heart Rhythm Society comprehensive guidelines for the management of atrial fibrillation. Can J Cardiol 2020;36:1847948.

32. Granger CB, Alexander JH, McMurray JJ, et al. Apixaban versus warfarin in patients with atrial fibrillation. N Engl J Med 2011;365:981-92.

33. Patel MR, Mahaffey KW, Garg J, et al. Rivaroxaban versus warfarin in nonvalvular atrial fibrillation. N Engl J Med 2011;365:883-91.

34. Saleiro C, Lopes J, De Campos D, et al. Left ventricular thrombus therapy with direct oral anticoagulants versus vitamin $\mathrm{K}$ antagonists: a systematic review and meta-analysis. J Cardiovasc Pharmacol Ther $2021 ; 26: 233-43$

35. Camilli M, Lombardi M, Del Buono M, et al. Direct oral anticoagulants versus vitamin $\mathrm{K}$ antagonists for the treatment of left ventricular thrombosis: a systematic review of the literature and meta-analysis. Eur Heart J Cardiovasc Pharmacother 2020:pvaa134.

36. Dalia T, Lahan S, Ranka S, et al. Warfarin versus direct oral anticoagulants for treating left ventricular thrombus: a systematic review and meta-analysis. Thromb J 2021;19:7.

37. Pisters R, Lane DA, Nieuwlaat R, et al. A novel user-friendly score (HAS-BLED) to assess 1-year risk of major bleeding in patients with atrial fibrillation: The Euro Heart Survey. Chest 2010;138:1093-100.
38. Giugliano RP, Ruff CT, Braunwald E, et al. Edoxaban versus warfarin in patients with atrial fibrillation. N Engl J Med 2013;369:2093-104.

39. Weinsaft JW, Kim HW, Crowley AL, et al. LV thrombus detection by routine echocardiography: Insights into performance characteristics using delayed enhancement CMR. JACC Cardiovasc Imaging 2011;4:702-12.

40. Celeste F, Muratori M, Mapelli M, Pepi M. The evolving role and use of echocardiography in the evaluation of cardiac source of embolism. J Cardiovasc Echogr 2017;27:33-44

41. Sedhom R, Abdelmaseeh P, Megaly M, Asinger R. Use of direct oral anticoagulants in the treatment of left ventricular thrombi: a systematic review. Am J Med 2020;133:1266-73.

42. Wang L, Meng H. Optimized antithrombotic therapy of acute myocardial infarction with left ventricular mural thrombus (OATH-AMI) Available at: https://clinicaltrials.gov/ct2/show/record/NCT03415386. Accessed February 7, 2021.

43. $\mathrm{Pu} \mathrm{J}, \mathrm{Ge} H$. Treatment of post-STEMI left ventricular thrombus with optimized anticoagulant (EARLYmyo-LVT). Available at: https://clinicaltrials.gov/ct2/show/record/NCT03764241. Accessed February 7, 2021.

44. Stewart R. A prospective randomized open, blinded end-point controlled study evaluating the resolution and recurrence of left ventricular thrombus with different anti coagulation strategies. Available at: https://www anzctr.org.au/Trial/Registration/TrialReview.aspx?id=375640. Accessed February 7, 2021.

\section{Supplementary Material}

To access the supplementary material accompanying this article, visit CJC Open at https://www.cjcopen.cal and at doi:10.1016/j.cjco.2021.04.007. 